\title{
A Study on the Decorative Patterns of Tibetan Buddhist Monastery Architecture
}

\author{
Miaomiao Liu \\ Architecture and Urban Planning College, Southwest Minzu University, Chengdu, China \\ Email: 1379012529@qq.com
}

How to cite this paper: Liu, M.M. (2019) A Study on the Decorative Patterns of Tibetan Buddhist Monastery Architecture. Open Journal of Social Sciences, 7, 355-361. https://doi.org/10.4236/jss.2019.74028

Received: March 22, 2019

Accepted: April 25, 2019

Published: April 28, 2019

Copyright $\odot 2019$ by author(s) and Scientific Research Publishing Inc. This work is licensed under the Creative Commons Attribution International License (CC BY 4.0).

http://creativecommons.org/licenses/by/4.0/

\section{(c) (i) Open Access}

\begin{abstract}
Architecture is the refuge of human beings, and Tibetan Buddhism is the spiritual sustenance of the Tibetan people. The monastery architecture produced by the combination of religious culture and architectural art makes us see a very characteristic religious architectural culture. Architectural decoration art is not only the product of culture, but also the embodiment of human artistic thought. Tibetan Buddhist monastery architecture is the essence of Tibetan architecture, and its decorative patterns are the comprehensive embodiment of religious culture and architectural art. The study of decorative patterns of religious architecture can more deeply understand the connotation of religious culture.
\end{abstract}

\section{Keywords}

Tibetan Buddhism, Monastery Architecture, Decorative Patterns

\section{Introduction to Tibetan Buddhist Monastery Architecture}

Tibetan Buddhism, commonly known as Lamaism, is a branch of Chinese Buddhism. There are five major denominations and Tibetan Benzism, respectively, Ningma School (Red Religion), Gelu School (Yellow Religion), GE Ju School (White Religion), Sakya School (Flower Religion), Chuenang School and Tibetan Native Benzism. Tibetan Buddhism is mainly popular in Tibetan, Mongolian, Turkish, Yugur and other minority areas, and widely spread in Tibet, $\mathrm{Si}$ chuan, Yunnan, Gansu, Qinghai, Xinjiang, Inner Mongolia and other provinces and autonomous regions in China (as shown in Figure 1). It permeates the political, economic, ideological and cultural fields of the society, and has a profound impact on the Tibetan people's outlook on life, values, morality and aesthetics. 


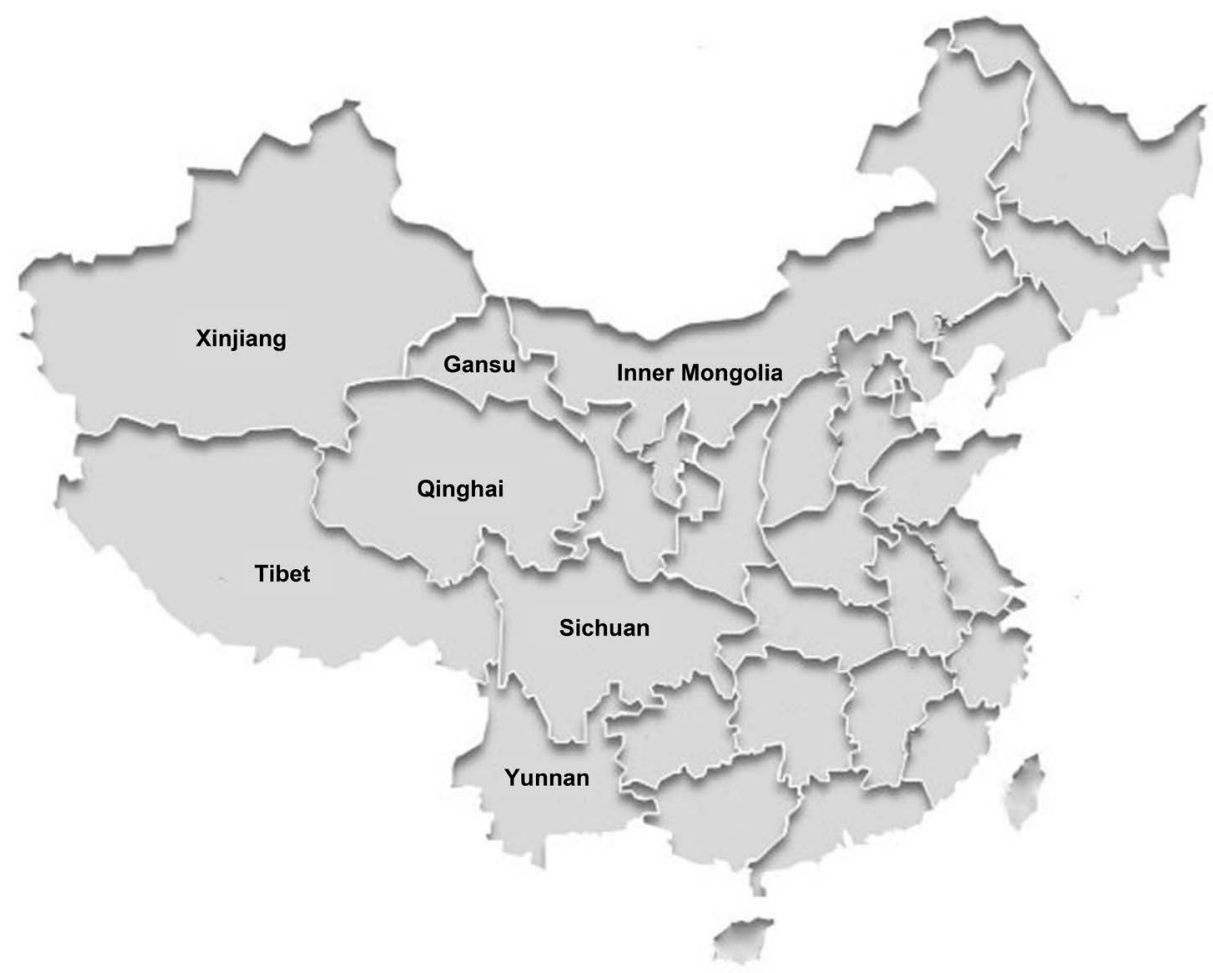

Figure 1. Distribution map of Tibetan Buddhist monasteries (author self-painting).

As the main carrier of Tibetan Buddhism, Tibetan Buddhist monasteries reveal the figure of religion from the shape of architecture to the internal environmental space, reflecting the highest achievements of Tibetan architectural art and technology. It is one of the important connotations of Tibetan architectural culture. Religion, as a complex cultural phenomenon, is closely related to art. The architectural art represented by spatial structure has been favored by religion in the first place because of the symbolism of architectural art. So that it can present the truth in consciousness and become a symbol of God in a perceptual and visual way. Tibetan Buddhist temples from the spatial layout to architectural construction will be this symbolic culture, from virtual to real, from large to small, from shallow to deep slowly implemented, in the form of architectural art inheritance and development.

As far as the scope of application of patterns is concerned, the decorative patterns with symbolic meaning are roughly divided into religious and secular; two major fields, Among them, the patterns used in the field of religion are used as a supplementary means to convey Buddhist ideas in addition to painting and sculpture by using visual language. The information transmitted by decorative patterns is not only very rich but also very large and esoteric in kind, which makes it difficult for many people to understand it [1].

Tibetan decorative patterns have a long history, and can be traced back to the prehistoric era; the initial development of decorative patterns originated from the demand for function; its initial function is anti-skid, reinforcement and indication. Beauty is only to meet its needs in addition to the spiritual pursuit, the 
aesthetic pursuit of patterns gave birth to the information expression of graphics, so that decorative patterns have the function of conveying information, the perfect decorative patterns at the same time have application, aesthetic and information functions. It has these functions in the decorative patterns of Tibetan Buddhist monastery architecture, which makes the religious atmosphere of monastery architecture more intense.

\section{Characteristics of Decorative Patterns of Tibetan Buddhist Monasteries}

\subsection{Characteristics of Decorative Patterns of Monasteries}

With the introduction and development of Buddhism, Tibetan Buddhist monasteries have gradually formed. at the same time, Sanye Temple, which has the three treasures of "Buddha, Dharma and Monk", has become the first Buddhist monastery in Tibet, which also marks the real emergence of Tibetan Buddhist monasteries. In the Tibetan Buddhist monastery architecture, according to the different architectural functions, it is generally composed of several parts of the building, such as scripture hall, Buddhist temple, Gaxia, Zakang and Kangcun and so on. The scripture hall is used for chanting sutras, the Buddhist temple is used for Buddhas, Gaxia is used as a religious office, Zakang is an attached Buddhist college, and Kangcun is the residence of lamas [2].

Scriptures and Buddhist temples as the main place to engage in religious activities, whether outside or inside the building, its decoration is mainly to render the religious atmosphere service. In order to emphasize the importance of the main building, the gilded top of the mountain was built on the flat roof of the monastery building, and decorated with ornaments with Buddhist connotation, such as the listening method of the two beasts, lotus, treasure pearl, Falun, pagoda victory building and so on. In the treatment of the external wall, the top eaves of the important buildings of the monastery use the Bian Ma wall, and the eaves of the buildings are painted brown, crimson or fruit color. Usually the horizontal lines are used to outline the outline of the building. the use of the horizontal lines not only increases the composition stability of the building, but also strengthens the unity and solemnity of the whole monastery complex.

In the temple building, the treatment of doors and windows focuses on the window eaves and lintels, the outer small and inner large windows, the window eaves hanging tricolor cloth mantle decoration. As the key point of decoration, the top-down decoration of the lintel consists of five layers at a time, such as lion's head, beam panel, jump beam, rafters and so on. The general outer door frame of the gate will have two or three layers of convex door frame decorated with carved curly grass, Buddha statues, lotus petals, scriptures and so on, so that the door of the temple hall is beautifully decorated and ornate in shape.

In addition, the wood structure, frame and components of important buildings have careful decorative design, carving or painting is the main decorative techniques, complex and exquisite decoration will render the temple architecture colorful. 


\subsection{Characteristics of Architectural Decorative Patterns}

The decorative patterns of Tibetan Buddhist monastery architecture are very rich, mainly divided into two categories: one is based on symbolic themes, the other is based on character themes, each of which contains many types.

Among them, symbolic themes include animals, plants, utensils, text and geometric patterns. Animal themes include goldfish, lions, white elephants, tigers, dragons and Phoenix. Plant themes such as lotus and other geometric plant flower decorative patterns and so on. Utensils such as Buddhist "eight treasures", diamond pestle and so on. "six words True words" is a typical text subject matter. Geometric patterns include circumflex patterns, Yongzhong patterns and so on. Each of its themes implies profound religious and cultural metaphors.

In the Buddhist "eight treasures", each of its utensils has a different meaning, and its patterns are frequently used in religious occasions and secular life. Umbrella, in Buddhist culture, is used to symbolize the escape of disaster and evil forces, but also symbolize authority and so on. Goldfish, its meaning has the wisdom of distinguishing right from wrong and choosing correctly. The fusion and coexistence of fish and water symbolizes transcendental liberation and eternal life with the intention of pursuing happiness. The bottle has the meaning of auspiciousness, cleanliness and financial resources. Miaolian, on behalf of purity, symbolizes the purity of its body, heart, language and meaning. White snail, symbol of strength and authority. Auspicious knot, meaning eternal, infinite, symbol of luck and wealth. In Buddhism, Shengli House means that the root of trouble and iniquity can be liberated and the right fruit of consciousness can be realized. The Falun, composed of hub, spoke and ring, symbolizes Buddhist doctrine with ethical wisdom and meditation. The above symbols are mainly used in building components (such as doors and windows, Liang Zhu, etc.) and indoor fabrics.

The subject matter of the characters includes the images of religious figures such as the King of Heaven, the Hercules, the Mother of Heaven (Buddha, Bodhisattva, Dumu) and so on. they are usually used on the walls of monasteries to set off the atmosphere of the Buddhist world in order to achieve the religious atmosphere embodied.

\subsection{Color Characteristics of Decorative Patterns}

In Tibetan Buddhist culture, the specific color has its specific meaning. the use of a certain symbol of Chinese style and a specific meaning of color to decorate monastery architecture, can strengthen and sublimate the connotation of architectural art and culture.

According to the Buddhist scriptures, career is included in the four areas of "interest", "increase", "Huai" and "Fu", and its expression is "interest" to indicate moderation, represented by white; "Zeng" means development, represented by yellow; and "Huai" means power. Represented by red; "volt" means ferocious, represented by black [3]. In simplification, interest and increase can be 
represented by white, and pregnancy and volt can be represented by red. This is why many of the temple murals we see use red, white, and blue faces, while demons and pagans use black red.

Because of the difference of regional nature, religious culture and aesthetic concept, the decorative color of monastery architecture is determined by its use environment and position, it has different emotional colors, such as red thick, golden rich, yellow noble, White pure, blue solemn, green quiet, black majesty and so on. The evil use of color can be seen everywhere in monastery architecture, whether it is roof, Liang $\mathrm{Zhu}$, doors and windows, internal and external walls and so on. In addition to the specific emotional color, each color element has different implications at the same time, and its use is also different. If red represents thick and heavy at the same time is a symbol of power, it is associated with dignified heroes and solemn religion, so red can not be easily used, only the monastery Buddhist temple, pagoda hall, Dharma hall and other important temple external walls can be used. Yellow symbolizes nobility, but also a higher level of color, yellow and yellow use similar, the use is very strict, generally used for monastery facade or gold roof decoration and so on.

White symbolizes purity and has the moral of happiness and beauty. the use of white in architecture can be traced back to the cultural tradition that the main line of Tibet is still white. In addition to buildings, Tibetan daily food, utensils and daily necessities are also often white, the local people have a long history of white feelings. In monastery architecture, white is mainly used in the white tower inside and outside the monastery and the exterior wall decoration of the monastery. Black symbolizes majesty, in Buddhist culture black has the meaning of dispelling demons, in temple architecture is mainly used in doors and windows and other places, black window frame and, door curtain is a major feature of Tibetan Buddhist temple architecture. In the interior building components and wall decoration patterns, mainly using red, yellow, blue, green, gold and other colors, through the proportion control of the most decorative form and theme color, the interior presents a brilliant pattern combination.

\section{Factors Affecting the Decorative Patterns of Tibetan Buddhist Monasteries}

As we all know, Tibetan culture has experienced the baptism of two different religious cultures. the early Benzo culture and Buddhism, which gradually became the mainstream culture after the $7^{\text {th }}$ century $\mathrm{AD}$, have a very profound impact on decorative patterns. So that the Tibetan traditional decorative patterns have always transmitted a strong religious meaning.

\subsection{Influence of Indian Buddhist Culture}

Buddhist culture was first introduced into the Central Plains from India and into Tibet later than the Central Plains, but because Tibet is the closest geographical location to India, it is directly influenced and radiated by Indian culture, so Ti- 
betan Buddhist culture. Closer to the primitive culture of Indian Buddhism. For example, a large number of metaphorical scriptures and symbols in monasteries. One of the most striking symbols is the Lama Tower (as shown in Figure 2). This form of tower composed of pedestal, covering and pagoda is very close to the prototype of the Indian pagoda. In the later period, the Lama Tower was attached by the Buddhist monks of the past dynasties. It contains more complex symbolic connotation, each part of the tower, has a very specific and subtle symbolic significance. It can be seen that the introduction of Indian Buddhism has a great impact on the decorative patterns of Tibetan Buddhist monastery architecture.

\subsection{The Influence of Tibetan Benzo Culture and Chinese Culture}

Tibetan Buddhism was first spread in Tibetan areas, and the original monastery architecture was also improved on the basis of Tibetan architecture and became a place to provide places for religious activities. With the spread of religion to Mongolia, the Central Plains and other areas outside the Tibetan areas, Tibetan architectural culture and Mongolian, Han and other ethnic cultures exchange and absorb each other, greatly enriching the original form. For example, some monasteries in Tibetan areas are influenced by the culture of dry boats in their architectural forms, structures or decorative techniques. In the Mongolian Lama Temple, from the overall layout to the single building are in the form of Tibetan architecture, some using the traditional temple architectural system in the Han Dynasty, some are combined with the traditional architecture in the Han Dynasty to optimize the new architectural form.

Up to now, Buddhist culture relies on the continuous development and growth of monastery carrier, which promotes the construction of a large number of monastery buildings, and also provides space for the development of monastery

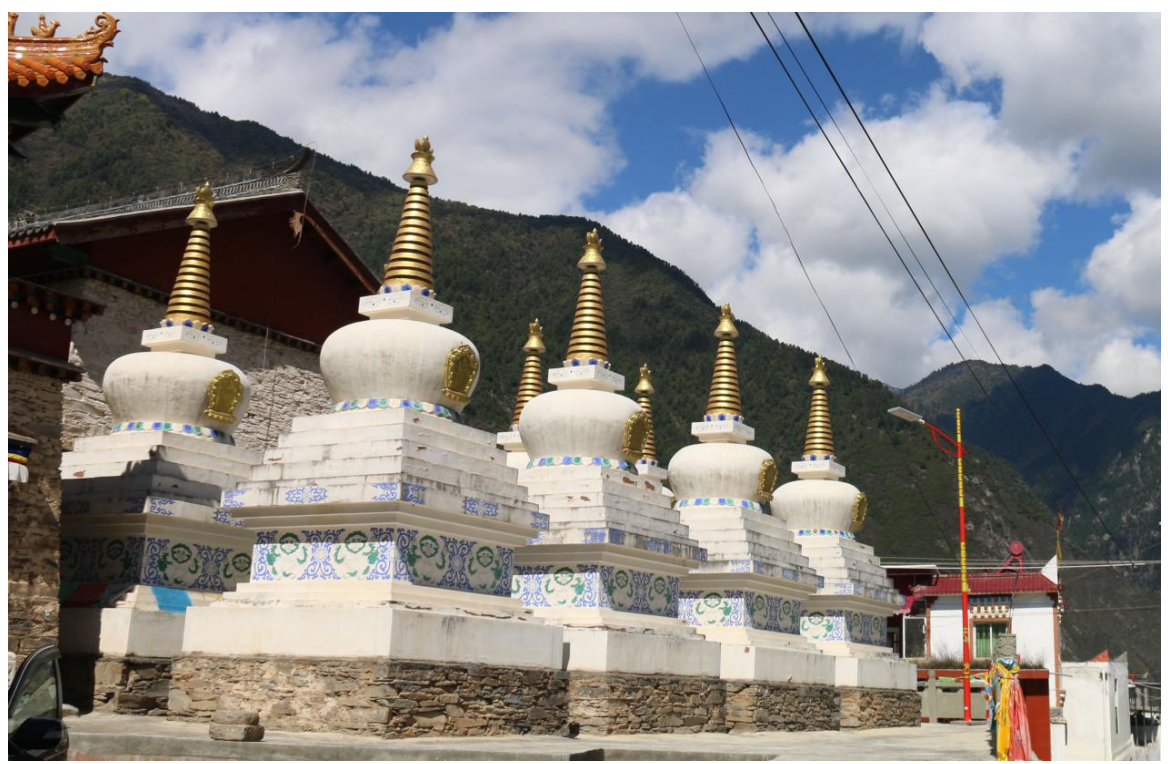

Figure 2. Lama Tower (author self-photo). 
architectural decorative patterns. In a word, the continuous spread and development of Tibetan Buddhist culture is the interaction of cultures of different nationalities and different regions, resulting in a unique architectural culture of Tibetan Buddhist monasteries. At the same time, it also greatly develops the decorative pattern art of Tibetan Buddhist monastery architecture.

\section{Conclusions}

The introduction of Buddhist culture and the integration of benzene religion want to become a unique Tibetan Buddhist culture. Tibetan Buddhist monastery architecture is the product of cultural exchange. The decorative culture in its monastery architecture does not lose its true colors in the process of circulation, forming a unique and distinct decorative art, reflecting the harmonious but different Tibetan Buddhist temple culture.

In the minority culture, Tibetan culture is undoubtedly the most complete, the most unique, the most self-contained system. The Tibetan Buddhism culture is perfectly embodied and interpreted through the temple architecture, and the architectural art of it is indispensable. With the rapid development of society, how to protect and inherit the architectural decoration culture of Tibetan Buddhist monasteries should be paid attention together. This paper is only a simple analysis of the architectural decorative patterns of Tibetan Buddhist monasteries. In order to inherit and protect the decorative culture of Tibetan monasteries, we still need to explore in depth.

\section{Note}

This project is funded by the graduate innovation research project of Southwest Minzu University, Project Name: Analysis on Decorative Patterns in Architectural Elements of Tibetan Buddhism, Project Number: CX2018SZ146.

\section{Conflicts of Interest}

The author declares no conflicts of interest regarding the publication of this paper.

\section{References}

[1] Gesandogi (2015) Tibetan Ornaments: Digital Tibetan Traditional Decorative Patterns. Tibet People's Publishing House, Lhasa, 12.

[2] Deng, C.L. (2016) Tibetan Monastery Architecture. Tibetan Ancient Books Publishing House, Lhasa.

[3] Qu, D.Y. and Shi, Y.H. (2003) A Preliminary Study on the Decorative Art of Tibe$\tan$ Buddhist Architecture. Journal of Pingdingshan Institute of Technology, 3. 